\title{
Ultrasonic atomizing-assisted spray drying: Effect on the quality of skimmed milk powders
}

\author{
Wangm, Y..$^{\mathbf{a}^{*}}$; Cui, Y. ${ }^{\mathrm{a}}$; Wang, B. ${ }^{\mathrm{b}}$; Zhang, M. $^{\mathrm{a}}$ \\ a State Key Laboratory of Food Science and Technology. Jiangnan University, Wuxi, China \\ b School of Food and Biological Engineering, Jiangsu University, Zhenjiang, China \\ *E-mail of the corresponding author: wyc453@163.com
}

\begin{abstract}
Skimmed milk powders (SMP) were produced by ultrasonic atomizingassisted spray drying (UASD). It was found that UASD can produce high quality SMP (with $<5 \%$ moisture content and $<2 \%$ insolubility) at lower inlet temperatures $\left(\sim 130^{\circ} \mathrm{C}\right)$. The particle size of the UASD-SMP was 10 times smaller (decreased from $\sim 20 \mu \mathrm{m}$ to $4 \mu \mathrm{m}$ ) than the tranditionally spray-dried SMP and the color appeal of UASD-SMP was also better ( $L^{*}$ value increased by $>6 \%$ ). Overall, this research shown that UASD can be used to produce small particle size and high quality SMP.
\end{abstract}

Keywords: Skimmed milk powder; ultrasonic atomization; spray dryer; particle size distribution; color 


\section{Introduction}

Atomizer is the key component of a spray dryer. It greatly affects the particle size and the quality of the final products. Rotary atomizer and pressure atomizer are the most commonly used atomizers in spray drying. Rotary atomizing produces droplets with a droplet size of 1$600 \mu \mathrm{m}$ whereas pressure atomizing generates droplets that ranged from $10-800 \mu \mathrm{m}{ }^{[1-2]}$. After water evaporation process, these droplets are generally dried to $>20 \mu \mathrm{m}$ dried particles ${ }^{[3]}$. Therefore, installation of a nano-micro sized automizer in a spray dryer is expected to obtain the dried products with a smaller particle size.

Ultrasonic atomizing possesses many advantages. It produces small droplets. and is easy for absorption in human digestive system. Unlike the traditional atomizing methods that rely on high pressure or high-speed motion to smash liquid samples, ultrasonic atomizing utilized the low ultrasonic vibration energy as the driven force ${ }^{[4]}$. Besides, by adjustment of the amplitude of the vibration, the atomizing speed can be precisely controlled. Therefore, the droplets produced by ultrasonic atomizing are more regular, uniform and smaller than those droplets generated by traditional atomizing methods ${ }^{[5]}$.

This research used fresh aqueous skimmed milk as the representative raw material. The relationships between the processing parameters (e.g. inlet temperature) and the product quality of ultrasound atomizing-assisted spray drying were systematically studied. The water content, solubility, color profile, protein content, particle size distribution, acidity, bulk density and microstructure of the final dried products were determined. These processing parameters and quality profiles were compared with those particles produced using a rotary atomizer-equipped spray dryer. The findings of this study contribute to the understanding and application of the atomizing-assisted spray drying.

\section{Materials and Methods}

\subsection{Materials}

Skimmed milk: Arla skimmed milk (1L, manufactured in Germany) was obtained from a Auchan supermarket in Wuxi. The skimmed milk contains $3.6 \mathrm{~g} / 100 \mathrm{~mL}$ protein, $0 \mathrm{~g} / 100 \mathrm{~mL}$ lipid, 5.1g/100mL carbohydrate, $50 \mathrm{mg} / 100 \mathrm{~mL}$ sodium and $120 \mathrm{mg} / 100 \mathrm{~mL}$ calcium.

\subsection{Methods}

\subsubsection{Experimental design and equipment}

The experimental design and related equipment is shown in Table 1 and Table 2, respectively. Regarding the experimental design, different inlet temperatures were used to analyses the effects of drying parameters on the quality of the ultrasound atomizing-assisted spray dried products. 
Table 1. Experimental design of this study

\begin{tabular}{ccc}
\hline Drying Methods & Inlet Temperature $\left({ }^{\circ} \mathrm{C}\right)$ & Quality analyses \\
\hline UASD & 110、130、150、170、190 & Water content、color profile、protein \\
RDSD & $130 、 150 、 170 、 190 、 210$ & content acidity bulk density \\
\hline
\end{tabular}

UASD-Ultrasound atomizing-assisted spray drying, RDSD-High-speed rotating dish spray drying

Table 2. Equipment used in this study

\begin{tabular}{|c|c|c|}
\hline Equipment & Product model & Manufacture \\
\hline High-speed rotating dish & QZR - 5 & Linzhou Drying Equipment Co., Ltd, \\
\hline Color meter & CR -400 & Canon Inc, Japan \\
\hline Electronic balance & PL 203 & Mettlet Toledo Co., Ltd, China \\
\hline Mastersizer & 2000 & Malvern Inc, England \\
\hline Scanning electro microscope & S-4800 & Hitachi Co., Ltd, Japan \\
\hline Lipid meter & SOX-406 & Hanon Instruments Co., Ltd, China \\
\hline Electric drying oven with & GZX-9140MBE & Boxunshiye Co., Ltd, China \\
\hline
\end{tabular}

\subsubsection{Research platform of UASD}

In this study, the ultrasonic atomizer was manufactured with 10 ultrasonic vibrators. The size of this ultrasonic atomizer is: $255 \mathrm{~mm}$ length $\times 90 \mathrm{~mm}$ width $\times 30 \mathrm{~mm}$ height. The oscillating frequency of the ultrasonic atomizer was $1.7 \mathrm{MHz}$ with a maximum atomizing capacity of $0.5 \mathrm{~kg} / \mathrm{h}$. The droplet size obtained by ultrasonic atomizing process was within the range of $2-10 \mu \mathrm{m}$. The temperature of the feed solutions was controlled by a combined temperature controller and feed-recycling system. The temperature controller was manufactured by Thermo Electron Co., Ltd (HAAKE DC10-K10, Germany), which works in the temperature range of $10-100^{\circ} \mathrm{C}$. The ultrasonic atomizing system is connected with a high-speed rotating dish spray dryer. The size of this spray dryer is $1600 \mathrm{~mm}$ length $\times$ $2200 \mathrm{~mm}$ width $\times 2500 \mathrm{~mm}$ height. The water evaporation capacity and the electrical heating powder of this spray dryer is $5 \mathrm{~kg} / \mathrm{h}$ and $16 \mathrm{KW}$, respectively. At the working stage, the rotary atomizer that equipped in the spray dryer was removed, and a thermal resistant tube was used to link the spray dryer and the ultrasonic atomizing system. The tube was inserted in the drying chamber with a reveal part of $\sim 200 \mathrm{~mm}$.

\subsubsection{Determination of the drying parameters of UASD and RDSD}

In order to achieve a desirable atomizing effect, skimmed milk have to be diluted and stored at a suitable temperature. A high concentration and low temperature environment results in a low atomizing capacity. However, if the temperature of the skimmed milk exceeds the protection range of the ultrasonic atomizer, the atomizing system will automatically close and stop working. We have done preliminary experiments and optimized the atomizing conditions (data not shown). In this study, the skimmed milk used 
for UASD was diluted by adding distill water at a milk to water ration of 1:2.5; The temperature of this diluted solution was controlled at $30-35^{\circ} \mathrm{C}$. The skimmed milk that used for RDSD was directly dried without any treatment.Regarding the atomizing capacity, the centrifuge frequency of high speed rotating dish spray dryer was $300 \mathrm{~Hz}$ with an atomizing capacity of $900 \mathrm{~mL} / \mathrm{h}$; the oscillating frequency of the ultrasonic atomizer was $1.7 \mathrm{MHz}$ with an atomizing capacity of $100 \mathrm{~mL} / \mathrm{h}$.

2.2.4. Measurements of the quality profiles of the skimmed milk powders produced by UASD and RDSD

Water content: water content of the SMP produced by the two drying methods was determined by an electric drying oven (Table 2) with forced convection according to a national standard method (GB/5009.3-2016) ${ }^{[6]}$.

Solubility: solubility of the SMP produced by the two drying methods was determined according to a national standard method (GB / 5413.29 - 2010) ${ }^{[7]}$.

Color profiles: color profiles of the SMP were measured by using a CR-400 color meter (Table 2). The L, a and b value represents the extent of white/black, red/green, yellow/blue color of the skimmed milk after drying, respectively.

Acidity: acidity of the SMP produced by the two drying methods was measured according to a national standard method (GB / 5009.239 - 2016) ${ }^{[8]}$.

Particle size: particle size of the dried products was determined by using a master sizer (Table 2) ${ }^{[9]}$. Each measurement was performed for triplicates and the average data was reported.

Microstructure: Morphological characteristics of the SMP produced by the two drying methods was determined by using S-4800 scanning electro microscope (Table 2). The acceleration voltage was $1.0 \mathrm{kv}$. The dried products were coated by a palladium-gold alloy coating instrument (manufactured by Bal-Tec. Inc). The scanning electro microscope images of SMP samples were captured within a range of 600 - 2400 magnifications.

\section{Results and Discussion}

\subsection{Water content of the dried SMP using UASD and RDSD as a function of different inlet temperatures}

As shown in Table 3, inlet temperature significantly affected water content of the SMP $(\mathrm{p}<0.05)$. Higher inlet temperatures resulted into a lower water content of the UASD-SMP and RDSD-SMP. At an inlet temperature of $\geq 170^{\circ} \mathrm{C}$, no significant difference was observed for the water content of UASD-SMP and RDSD-SMP samples ( $p>0.05)$. When inlet temperature was $\leq 150^{\circ} \mathrm{C}$, the water content of UASD-SMP was lower than that of RDSDSMP. The water content of the RDSD-SMP was $>5 \%$ at an inlet temperature of $130^{\circ} \mathrm{C}$. 
However, the water content of the UASD-SMP was below this national acceptable moisture content at an inlet temperature of $110^{\circ} \mathrm{C}$. The findings of this section indicate that lower inlet temperature (of spray drying) was required to achieve an acceptable water content of SMP by applying UASD method. This was attributed to the small droplet size of ultrasonic atomizing, which allows the fast evaporation of water.

Table 3. Water content of the skimmed milk powders obtained by UASD and RDSD

\begin{tabular}{ccccccc}
\hline Inlet temperature $\left({ }^{\circ} \mathrm{C}\right)$ & 110 & 130 & 150 & 170 & 190 & 210 \\
\hline UASD-SMP & 4.317 & $4.091^{\mathrm{a}}$ & $2.524^{\mathrm{a}}$ & $2.145^{\mathrm{a}}$ & $1.601^{\mathrm{a}}$ & - \\
RDSD-SMP & - & $5.241^{\mathrm{b}}$ & $3.105^{\mathrm{b}}$ & $2.075^{\mathrm{a}}$ & $1.574^{\mathrm{a}}$ & 1.445 \\
\hline
\end{tabular}

*The data with different superscript at a same column is significantly different $(\mathrm{p}<0.05)$.

\subsection{Solubility of the dried SMP using UASD and RDSD as a function of different inlet temperature}

At a certain extent, changes of solubility of SMP indicates the denaturation of proteins. Thus, low SMP solubility could be resulted by the denaturation of its protein component, negatively affecting its rehydration performance. Furthermore, different particle size of the dried powders also contributes to the varied solubilities of SMP.

As shown in Table 4. Solubility of the UASD-SMP decreased significantly with an increased inlet temperature $(\mathrm{p}<0.05)$. At an inlet temperature of $\leq 130^{\circ} \mathrm{C}$, the solubility of UASD-SMP was 98.66-98.97\% (meets the national standard of $>97 \%$ ); At an inlet temperature of $>130^{\circ} \mathrm{C}$, the solubility of UASD-SMP decreased sharply to $89.72-95.01 \%$. Regarding the RDSD-SMP, the dried powders possessed a solubility of $>97 \%$ within the whole inlet temperature range of $110^{\circ} \mathrm{C}-210^{\circ} \mathrm{C}$. Overall, these findings indicated that solubility of the UASD-SMP was susceptible to inlet temperatures of spray drying. High inlet temperature $\left(>130^{\circ} \mathrm{C}\right)$, small droplets size and tiny dried particles caused the denaturation of proteins component in SMP and significantly reduced its solubility $(\mathrm{p}<0.05)$.

Table 4. Solubility of the skimmed milk powders obtained by UASD and RDSD.

\begin{tabular}{lcccccc}
\hline Inlet temperature $\left({ }^{\circ} \mathrm{C}\right)$ & 110 & 130 & 150 & 170 & 190 & 210 \\
\hline UASD-SMP & 98.66 & $98.97^{\mathrm{a}}$ & $95.01^{\mathrm{a}}$ & $90.79^{\mathrm{a}}$ & $89.72^{\mathrm{a}}$ & - \\
RDSD-SMP & - & $98.95^{\mathrm{a}}$ & $97.82^{\mathrm{b}}$ & $97.83^{\mathrm{b}}$ & $97.71^{\mathrm{b}}$ & 97.96 \\
\hline
\end{tabular}

*The data with different superscript at a same column is significantly different $(\mathrm{p}<0.05)$.

\subsection{Color profile of the dried SMP using UASD and RDSD as a function of different inlet temperature}

The color profiles of UASD-SMP and RDSD-SMP are provided in Table 5. As shown in Table 5. Inlet temperature of the spray drying processes did not cause significant effects on the lightness color of SMP ( $>>0.05$ ). However, the UASD-SMP was significantly lighter 
than RDSD-SMP $(\mathrm{p}<0.05)$. Inlet temperature of the spray drying processes significantly affected the $a^{*}$ value of SMP $(p<0.05)$. High inlet temperature decreased the $a^{*}$ value. At the same inlet temperatures, $a^{*}$ value of the UASD-SMP was significantly lower than that of the RDSD-SMP. This means that the UASD-SMP samples were less red than RDSDSMP. High inlet temperature increased the $b^{*}$ value. At the same inlet temperatures, $b^{*}$ value of the UASD-SMP was significantly higher than that of the RDSD-SMP, indicating a more yellowness color.

Table 5.color value of the skimmed milk powders obtained by UASD and RDSD

\begin{tabular}{lccccccc}
\hline Inlet temperature $\left({ }^{\circ} \mathrm{C}\right)$ & color value & 110 & 130 & 150 & 170 & 190 & 210 \\
\hline \multirow{2}{*}{ UASD-SMP } & $L^{*}$ & 98.31 & $97.47^{\mathrm{a}}$ & $97.81^{\mathrm{a}}$ & $97.55^{\mathrm{a}}$ & $97.42^{\mathrm{a}}$ & - \\
& $a^{*}$ & $-2.65^{\mathrm{a}}$ & $-2.42^{\mathrm{a}}$ & $-2.53^{\mathrm{a}}$ & $-2.58^{\mathrm{a}}$ & $-3.02^{\mathrm{a}}$ & - \\
& $b^{*}$ & 11.28 & $11.61^{\mathrm{a}}$ & $12.08^{\mathrm{a}}$ & $13.03^{\mathrm{a}}$ & $14.66^{\mathrm{a}}$ & - \\
RDSD-SMP & $L^{*}$ & - & $95.25^{\mathrm{b}}$ & $95.62^{\mathrm{b}}$ & $96.23^{\mathrm{b}}$ & $96.55^{\mathrm{b}}$ & 95.36 \\
& $a^{*}$ & - & $-2.22^{\mathrm{b}}$ & $-2.02^{\mathrm{b}}$ & $-2.38^{\mathrm{b}}$ & $-2.71^{\mathrm{b}}$ & -3.22 \\
& $b^{*}$ & - & $10.05^{\mathrm{b}}$ & $9.68^{\mathrm{b}}$ & $10.21^{\mathrm{b}}$ & $10.65^{\mathrm{b}}$ & 12.51 \\
\hline
\end{tabular}

*The data with different superscript at a same column is significantly different $(\mathrm{p}<0.05)$.

\subsection{Acidity of the dried SMP using UASD and RDSD as a function of different inlet temperature}

Acidity of the UASD-SMP and RDSD-SMP samples is presented in Table 6. The acidity of both UASD-SMP and RDSD-SMP were lower than the national standard value of $18^{\circ} \mathrm{T}$. UASD-SMP was more acidic than RDSD-SMP, indicating the less oxidation occurred during the drying process. This might be due to the shorter water evaporation period and lower inlet drying temperature of the UASD process.

Table 6. Acidity of the skimmed milk powders obtained by UASD and RDSD

\begin{tabular}{cc}
\hline Drying Methods & Acidity $\left({ }^{\circ} \mathrm{T}\right)$ \\
\hline UASD (inlet temperature of $\left.130^{\circ} \mathrm{C}\right)$ & $15.91^{\mathrm{a}}$ \\
RDSD(inlet temperature of $\left.170^{\circ} \mathrm{C}\right)$ & $16.89^{\mathrm{b}}$ \\
\hline
\end{tabular}

*The data with different superscript at a same column is significantly different $(\mathrm{p}<0.05)$.

\subsection{Particle size of the dried SMP using UASD and RDSD}

The average particle size and particle size distribution of the UASD-SMP and RDSD-SMP samples is presented in Fig. 1 . The particle size of UASD-SMP was $>5$ times smaller than that of RDSD-SMP samples. This is due to the differences between the droplets produced by ultrasonic atomizing and high-speed rotary atomizing. The ultrasonic atomized droplet size was in a range of 2-10 $\mu \mathrm{m}$, and hence the surface area to contact the drying medium was enlarged enormously. This not only resulted into a fast water evaporation period, but also significantly reduced the particle size of SMP $(\mathrm{p}<0.05)$. 


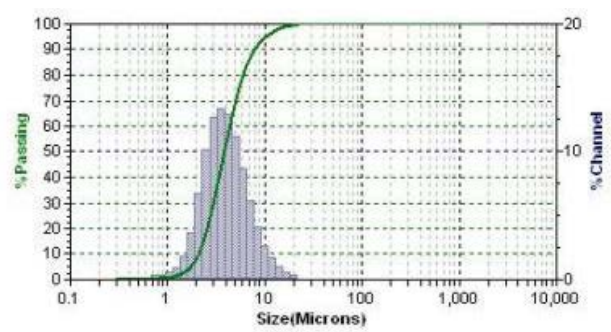

(A)

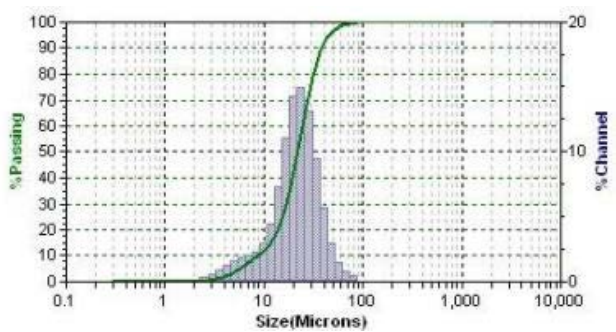

(B)

Fig.1 Particle size distribution of (A) UASD-SMP obtained at $130^{\circ} \mathrm{C}$ inlet temperature and (B) RDSD-SMP obtained at $150^{\circ} \mathrm{C}$ inlet temperature

\subsection{Morphological characteristics of the dried SMP using UASD and RDSD}

The morphology of SMP samples were monitored by scanning electro microscopy (Fig.2). The particles obtained through UASD were much smaller than those produced by RDSD, which was also confirmed by the laser diffraction measurements as mentioned in section 3.5. The UASD particles were irregular, shrunk and compacted; the microstructure of RDSD particles was spherical, uniformly distributed and loosely organized with a few broken skins. These differences in microstructure of SMP might explain the lower solubility of UASD-SMP, e.g. the uniformity of UASD-SMP was lower than that of RDSD-SMP, the structure of UASD-SMP was more compact than RDSD-SMP.

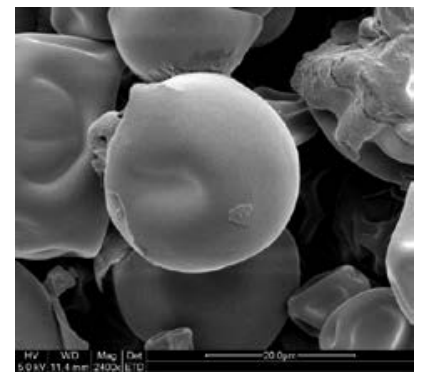

RDSD-SMP ( $\times 2400$ magnification)

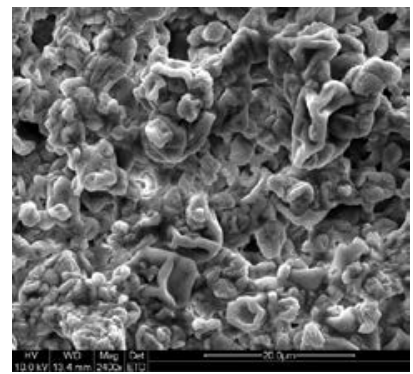

UASD-SMP (×2400 magnification)

Fig. 2 Scanning electro microscopy images of the dried SMP using UASD and RDSD

\section{Conclusions}

This research systemically compared and studied the quality aspect of SMP obtained by a novel drying method. The innovative UASD is expected to produce high quality and small particle size SMP. UASD required as low as $110^{\circ} \mathrm{C}$ inlet temperature to obtain dried SMP ( $<5 \%$ water content), which was almost $50^{\circ} \mathrm{C}$ lower than the inlet temperatures used for the traditional spray drying. Furthermore, the particle size of the UASD-SMP $(\sim 4 \mu \mathrm{m})$ was $>5$ times smaller than that of the RDSD-SMP. The color appeal of the UASD-SMP was $>6 \%$ lighter than that of the RDSD-SMP. These findings indicated that UASD is a promising 
drying method to produce high quality powders for food and pharmaceutical industries. However, there are still a few scientific issues have not been solved for the UASD method. E.g. the atomizing capacity of high-solid content solutions is relatively low; the final dried products is difficult to collect though the gas-solid separator that designed for the traditional spray drying. Therefore, further research on UASD is recommended to be carried out in the drying field.

\section{Acknowledgement}

This research was funded by the Open Project Program of the State Key Lab of Advanced Manufacturing Equipment Technology of Food (Grant No. BM2014007), Jiangnan University.

\section{References}

[1] Nandiyanto A. B. D., Okuyama K. Progress in developing spray-drying methods for the production of controlled morphology particles: From the nanometer to submicrometer size ranges. Advanced Powder Technology, 2011, 22(1):1-19.

[2] Mujumdar A. S. Handbook of Industrial Drying, third edition. New York, CRC Press, 2006, 215-254.

[3] Filkova I., Huang L.X., Mujumdar A.S. Industrial spray drying systems. In Handbook of Industrial Drying; Mujumdar, A.S., Ed.;CRC Press: New York, 2007; 215-254.

[4] Julianna C. Simon, Oleg A. Sapozhnikov, Vera A. Khokhlova, et al. Ultrasonic atomization of liquids in drop-chain acoustic fountains. Journal of Fluid Mechanics , 2015 , 766 :129-146.

[5] Huang H., Yao X., Wang M. Q., Wu X. Q. The measurements of atomizing properties of ultrasonic atomizing system. Piezoelectrics \& Acoustooptics (in Chinese), 2004, 26(1): 62-64.

[6] Determination of water content in foods. National Standard of China, GB/T 5009.3-2016; Standardization Administration of the P.R. China: Peking, 2016.

[7] Determination of solubility in foods for infants and young children, milk and milk products. National Standard of China, GB/T 5413.29-2010; Standardization Administration of the P.R. China: Peking, 2010 .

[8] Determination of acidity in foods. National Standard of China, GB/T 5009.2392016; Standardization Administration of the P.R. China: Peking, 2016.

[9] Wang B., Timilsena Y. P., Blanch E., et al. Characteristics of bovine lactoferrin powders produced through spray and freeze drying processes. International Journal of Biological Macromolecules, 2017, 95:985-994. 